\title{
Topical Application of Rosa multiflora Root Extract Improves Atopic Dermatitis-Like Skin Lesions Induced by Mite Antigen in NC/Nga Mice
}

\author{
Kwan Hee Park, ${ }^{a}$ Mi Sook Jeong, ${ }^{b}$ Kwang Jun Park, ${ }^{a}$ Young Wook Choi, ${ }^{a}$ \\ Seong Jun Seo, ${ }^{* b}$ and Min Won Lee*,a \\ ${ }^{a}$ College of Pharmacy, Chung-Ang University; and ${ }^{b}$ College of Medicine, Chung-Ang University; 221 Heukseok-Dong, \\ Dongjak-Gu, Seoul 156-756, Korea. \\ Received August 6, 2013; accepted October 20, 2013
}

The roots of Rosa multiflora THunb. (RM) has been used in oriental traditional medicines as remedies for scabies, rheumatic arthralgia and stomatitis which were practicably related with today's inflammatory and allergic diseases. In the present study, we evaluated whether RM root extract (RME) and its major constituent, 2-(3,4-dihydroxyphenyl)-6-(4-hydroxyphenyl)-8-(2,4-dihydroxyphenyl)-2,3-trans-6,7-cis-7,8-trans3,4,7,8-tetrahydro-2H,6H-pyrano[2,3- $f]$ chromene-3,7,9-triol (RM-3) belongs to condensed tannins, improve atopic dermatitis (AD)-like skin lesions in NC/Nga mice induced by mite antigen. Topical application of RME as well as RM-3 improved skin severity and suppressed mRNA levels of inducible nitric oxide synthase (iNOS) and cyclooxygenase-2 (COX-2) on skin tissues, in addition, significantly reduced T helper 2 (Th2) immune responses via interleukin 10 (IL-10) up-regulation. Thus, RME, contains lots of condensed tannins such as RM-3 which possesses potent anti-inflammtory and immune-modulatory effects, may be useful for treatment of skin allergies and can be developed as new alternative herbal therapy against AD.

Key words Rosa multiflora; Rosaceae; condensed tannin; proanthocyanidin; phlobatannin; atopic dermatitis

Atopic dermatitis (AD) is a chronic inflammatory skin disease characterized by pruritic and eczematous skin lesion. This disease primarily occurs in infants and children, and the incidence is gradually increasing in developing as well as developed countries. Although the cause of AD has been still unclear, it has been understood as immune disorder characterized by increased immunoglobulin $\mathrm{E}(\mathrm{IgE})$ and $\mathrm{T}$ helper 2 (Th2) cytokine levels as well as presence of blood eosinophilia. ${ }^{1)}$ Meanwhile, topical corticosteroids have been widely used as the main therapeutic strategy against $\mathrm{AD}$, however they could only be used for short periods of time and in limited skin regions because of serious adverse effects such as aggravation and recurrence. ${ }^{2)}$ Therefore, the demands of alternative therapies for AD have been increasing.

Rosa multiflora ThunB. (RM), called as multiflora rose, baby rose, many-flowered rose and seven-sisters rose, is native to Eastern Asia. While RM has been used as rootstock for ornamental roses in Western, all parts of RM has been known as folk medicine in Eastern. Especially, hips have been widely used as diuretics and also registered on Korean and Japanese Pharmacopoeia. Meanwhile, root of RM have been rarely researched in recent year although it has been traditionally used for rheumatism, scabies and stomatitis. ${ }^{3)}$ In our previous works, condensed tannins including novel stereoisomers (RM-1, 2 and 3) as well as catechin (CAT), and procyanidin B-3 (ProB3) were isolated from the roots of RM, and RM-1 and ProB3 showed to improve AD-like skin lesion in vivo. ${ }^{4,5}$ As part of the research for development of herbal new drug, the present study was conducted to evaluate therapeutic effects of RM root extract (RME) as well as additional main compound, RM-3, belongs to phlobatannin which is a kind of distinctive condensed tannin on the mite antigen-induced ADlike skin lesion in $\mathrm{NC} / \mathrm{Nga}$ mice.

\section{MATERIALS AND METHODS}

Isolation and Preparation RM-3 and RME were prepared as described earlier. ${ }^{4}$ Briefly, the roots of RM were purchased on Gyeongdong Market (Seoul, Korea) in March 2008, and identified by Prof. Min Won Lee from Chung-Ang University. The voucher specimen (RMR2008) was deposited at the herbarium of the College of Pharmacy, Chung-Ang University, Korea. The roots of RM $(2.5 \mathrm{~kg})$ were extracted three times with $80 \%$ acetone $(18 \mathrm{~L}, 2 \mathrm{~d}$ each) at room temperature. After removing the acetone under vacuum, the residual aqueous solution was filtered and the filtrate was then concentrated (RME, $215 \mathrm{~g}$ ). This extract was subjected to Sephadex LH-20 (10-25 $\mu \mathrm{m}$, GE Healthcare Bio-Science AB, Uppsala, Sweden) ( $2 \mathrm{~kg}, 10 \times 80 \mathrm{~cm}$ ) and eluted with $\mathrm{H}_{2} \mathrm{O} / \mathrm{MeOH}$ gradient system to afford 3 sub-fractions. Next, fraction 2 (14 g) was subjected to MCI-gel CHP20P (75-150 $\mu \mathrm{m}$, Mitsubishi Chemical, Tokyo, Japan) $(600 \mathrm{~g}, 5 \times 60 \mathrm{~cm})$ with $\mathrm{H}_{2} \mathrm{O} / \mathrm{MeOH}$ gradient system and yielded RM-3 (1.5 g) (Fig. 1).

Quantitative Analysis of Condensed Tannins Quantification of condensed tannins including RM-3 previously isolated from $\mathrm{RME}^{4)}$ was performed using Waters 600 high-<smiles>Oc1ccc([C@@H]2Oc3c(c(O)cc4c3[C@@H](c3ccc(O)cc3O)[C@H](O)[C@H](c3ccc(O)c(O)c3)O4)C[C@H]2O)cc1</smiles>

Fig. 1. Structure of RM-3, Isolated from the Roots of Rosa multiflora 
performance liquid chromatography (HPLC) system (Waters Corp., Milford, MA, U.S.A.). Samples were separated using a Kromasil $100-5$ C18 column $(250 \times 4.6 \mathrm{~mm}$ i.d., $5 \mu \mathrm{m})$ (AkzoNobel, Bohus, Sweden), with the water-methanol gradient elution $(10 \% \rightarrow 40 \% \mathrm{MeOH})$ at $280 \mathrm{~nm}$ UV wavelengths during $30 \mathrm{~min}$. The flow rate was $1 \mathrm{~mL} / \mathrm{min}$ and the injection volume was $20 \mu \mathrm{L}$. The amount of each compound was calculated by peak area of $4 \mathrm{mg} / \mathrm{mL}$ RME based on calibration curve of serially diluted-standard samples (50, 100, 200, 300 and $400 \mu \mathrm{g} / \mathrm{mL}$ ). The concentrations of ProB3, CAT, RM-1, RM-2 and RM-3 were $30.23 \pm 1.15,54.76 \pm 2.32,85.12 \pm 4.13,26.79 \pm$ 0.98 and $17.38 \pm 0.56 \mu \mathrm{g} / \mathrm{mg}$ dry extract, respectively (data not shown). The sum of them was over $20 \mathrm{w} / \mathrm{w} \%$, thus condensed tannins must be contained mainly from RME.

Animals Twenty female 5 week-old NC/Nga mice (Charles River Co., Ltd., Yokohama, Japan) were maintained under conventional condition on a $12 \mathrm{~h}$ light/ $12 \mathrm{~h}$ dark cycle with food and water ad libitum. The temperature of the colony room was maintained at $22-23^{\circ} \mathrm{C}$ and humidity $55 \pm$ $15 \%$. Animal treatment and maintenance were carried out in accordance with the Guide for the Care and Use of Laboratory Animals of National Institutes of Health (NIH publication No. 85-23, revised 1996) and approved by the Animal Care and Use Committee of the Chung-Ang University of Korea.

Induction of AD-Like Skin Lesion After shaving the animals' back hair by clipper, $100 \mathrm{mg}$ of mite cream (Biostir Inc., Kobe, Japan) impregnated with Dermatophagoides farina crude extract was applied to dorsal skin twice a week until 18 weeks of age. Each gram of this cream contained $234 \mu \mathrm{g}$ of Der f $1,7 \mu \mathrm{g}$ of Der f 2 and $136.4 \mathrm{mg}$ of proteins.

Topical Application of RM-3 and RME After induction of AD-like skin lesion, the animals were divided into 4 groups, and each group contained 5 mice, respectively. Each group was then topically treated with 1\% RM-3, RME (experimental group), $0.1 \%$ hydrocortisone (positive control) in base cream, or only base cream (negative control) every day during 4 weeks. The base cream was prepared as o/w emulsion which contained suitable combination of oil phase $(5 \%$ stearic acid, $2 \%$ cetyl alcohol, and $7 \%$ mineral oil) and aqueous phase (10\% glycerin, $3 \%$ polyglyceryl-3-metyl glucose distearate and water).

Evaluation of Skin Severity The severity of dermatitis was assessed macroscopically by the following scoring procedure. The total scores of the skin severity were defined as the sum of the individual score $(0$, no symptoms; 1 , mild; 2 , moderate; 3 , severe) for each of the following seven signs like erythema, hemorrhage, edema, excoriation, erosion, scaling and dryness. ${ }^{6)}$ And, the severity was monitored by taken photographs once a week.

Real-Time Quantitative Polymerase Chain Reaction (qPCR) Skin tissue biopsies were collected from the ADlike skin lesion in NC/Nga mice, and total RNA was isolated using $1 \mathrm{~mL}$ of TRIzol reagent (Invitrogen, Carlsbad, CA, U.S.A.). After $0.2 \mathrm{~mL}$ of chloroform was added and shaken vigorously by hands for $15 \mathrm{~s}$, the mixtures were centrifuged with $12000 \mathrm{rpm}$ at $4^{\circ} \mathrm{C}$ for $15 \mathrm{~min}$. The upper aqueous phase was transferred to a fresh tube, and the same amount of 2-propanol was added. After mixtures were incubated at $4^{\circ} \mathrm{C}$ for $15 \mathrm{~min}$, it was centrifuged with $12000 \mathrm{rpm}$ at $4^{\circ} \mathrm{C}$ for $15 \mathrm{~min}$. The supernatant was removed, and then washed $500 \mu \mathrm{L}$ of $70 \%$ ethanol with $12000 \mathrm{rpm}$ at $4^{\circ} \mathrm{C}$ for $5 \mathrm{~min}$. The RNA pellet was briefly dried. The purified RNA was dissolved in diethyl pyrocarbonate-distilled water (DEPC-DW). The total RNA was reverse transcripted at $42^{\circ} \mathrm{C}$ for $30 \mathrm{~min}$ in a containing reverse transcriptase (TaKaRa, Shiga, Japan), 10X buffer, $10 \mathrm{~mm}$ deoxyribonucleotide triphosphate (dNTP) (dNTP mix), oligo dT primer, RNase inhibitor, $25 \mathrm{mM} \mathrm{MgCl}_{2}$. The $2 \mu \mathrm{L}$ of each cDNA sample from the RT-PCR was amplified by PCR in $25 \mu \mathrm{L}$ containing $10 \mathrm{X}$ buffer $2.5 \mu \mathrm{L}, 25 \mathrm{mM} \mathrm{MgCl}_{2} 2.5 \mu \mathrm{L}$ and $10 \mathrm{pmol} 0.75 \mu \mathrm{L}$ primer. PCR was experimented $10 \times$ buffer for Taq polymerase (100mm Tris- $\mathrm{Cl} \mathrm{pH} 8.5,400 \mathrm{~mm} \mathrm{KCl}$ ), $1 \mathrm{~mm}$ dNTP each, $50 \mathrm{~mm} \mathrm{MgCl}_{2}$, upstream primer $(5 \mu \mathrm{M})$, downstream primer $(5 \mu \mathrm{M})$, DNA template (less than $200 \mathrm{ng}$ ) SyBr Green I. The specific primer sequences of each gene were as follows: inducible nitric oxide synthase (iNOS) (65 bp): 5'-CTG ATG CCT CTT CCA GGT GT-3' (sense), 5'-GAG GGA GCC CTT TCT GAA TC-3' (anti-sense)/cyclooxygenase (COX)-2 (80 bp): 5'-CCA CCC ATG GCA AAT TCC ATG GCA-3' (sense), 5'-GGT GCT GCT TGT TAG GAG GTC AAG TAA AGG GC-3' (anti-sense)/glyceraldehyde3-phosphate dehydrogenase (GAPDH) (93 bp): 5'-CCA CCC ATG GCA AAT TCC ATG GCA-3' (sense), 5'-CCC TGT TGC TGT AGC CGT AT-3' (anti-sense).

Measurement of Eosinophil Ratio Thirty microliter of each capillary blood six fold diluted with $150 \mu \mathrm{L}$ of saline. And, eosinophil ratio was measured by Sysmex XE-2100 hematology analyzer.

Measurement of IgE Levels The amount of total IgE in the serum was determined by a sandwich enzyme-linked immunosorbent assay (ELISA). Briefly, 96-well plates for ELISA were coated with anti-mouse $\operatorname{IgE}$ antibody $(\mathrm{Ab})$ by incubation overnight at $4{ }^{\circ} \mathrm{C}$, and then were treated further with $2 \%(\mathrm{w} / \mathrm{v})$ bovine serum albumin (BSA) dissolved in phosphate buffered saline (PBS) containing 0.05\% Tween 20 (PBST) for $2 \mathrm{~h}$ at room temperature to block any nonspecific binding. Next, serial dilutions of the serum samples were incubated in the wells in duplicate for $1 \mathrm{~h}$ at room temperature. After being washed three times with PBST, biotin-conjugated rat anti-mouse IgE $\mathrm{Ab}$ (LO-ME-2) was added to the wells, followed by the addition of streptavidin-peroxidase (Seikagaku Corp., Tokyo, Japan). After washing three times, the plates were developed using a substrate solution containing $0.04 \% O$-phenylenediamine dissolved in phosphate citrate buffer $(\mathrm{pH} 5.0)$. The reactions were terminated by the addition of sulfuric acid. The plates were read in a microplate reader at $490 \mathrm{~nm}$, and the amount of the Ig isotype was calculated by comparing it with the mouse IgE standard (Pharmingen, CA, U.S.A.).

Measurement of Th2-Related Cytokine Levels The serum Th2 cytokines (interleukin (IL)-4, 5 and 13) levels were measured with mouse cytokine enzyme immunoassay kit (R\&D Systems, Minneapolis, MN, U.S.A.).

Statistical Analysis All data were expressed as the means \pm S.D. The statistical differences in skin severity score were analyzed by Mann-Whitney $U$-test in order to compare negative control with experimental groups on each week, and assessed by Wilcoxon's signed-ranks test for time-course comparison on each topical treatment. The differences of mRNA levels and Th2 cytokines were assessed by one-way ANOVA followed by Student-Newman-Keuls (S-N-K) test for multiple comparison. In addition, the difference of eosinophil ratio and IgE levels were assessed by paired $t$-test in order to compare before and after each topical treatment. The $p$ values were less 


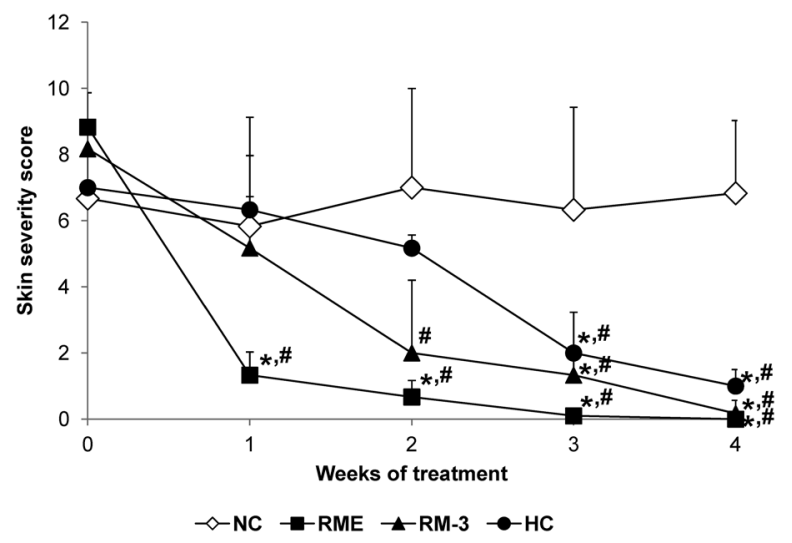

Fig. 2. Effect of RM-3 and RME on the Total Clinical Severity Scores

The application of mite cream to the back of mice induced AD-like skin lesions. and ProB3 and RM-1 treated topically for 4 weeks. The total clinical severity score was defined as the sum of scores for seven clinical criteria: erythema, hemorrhage, edema, excoriation, erosion, scaling and dryness. Results are expressed as mean \pm S.D. $(n=5) . * p<0.05$ versus negative control of each week. ${ }^{*} p<0.05$ versus each group before topical treatment. NC, negative control; $\mathrm{HC}$, hydrocortisone.

than 0.05 were considered to be significantly different.

\section{RESULTS}

Effects on Clinical Skin Severity The clinical skin severity of AD-like skin lesion was evaluated by modified SCORAD method, on scoring seven major clinical symptoms of AD: erythema, hemorrhage, edema, excoriation, erosion, scaling and dryness. ${ }^{6}$ AD-like skin lesions were induced by the treatment of mite antigen on the back of $\mathrm{NC} / \mathrm{Nga}$ mice twice a week and the clinical symptoms of $\mathrm{AD}$ got worsen until 18 weeks of age. Topical application of RM-3 and RME dramatically improve AD-like skin lesion, and significantly lowered clinical skin severity scores during experimental period $(p<0.05)$ (Fig. 2). In the final week of the experiment, any clinical signs were not observed in the topical application of both RME and RM-3, as almost same as that of positive control (Fig. 2). These results indicated that RME as well as RM-3 could effectively improve skin severity of mite-induced AD-like skin lesions in NC/Nga mice.

Effects on mRNA Levels of iNOS and COX-2 Because $\mathrm{AD}$ has been characterized as skin inflammatory disease, we determined mRNA levels of iNOS and COX-2, well-known to involve inflammatory response, in skin tissue of AD-like skin lesion via Real-time PCR. ${ }^{7)}$ Consequently, RM-3 and RME significantly suppressed respective mRNA levels of iNOS and COX-2 compared to negative control $(p<0.05)$ (Fig. 3). These results indicated that RM-3 and RME should improve skin inflammation of AD-like skin lesions induced by mite on $\mathrm{NC} /$ Nga mice.

Effects on Eosinophil Ratio and IgE Level Elevation of eosinophil and abnormal high IgE level are representative indicator on allergic disease such as $\mathrm{AD} .^{8,9)}$ Thus, we measured changes of eosinophil ratio and $\operatorname{IgE}$ level before and after treatment of RM-3 and RME using haematology automated analyser and sandwich ELISA, respectively. Topical application of RM-3 and RME for 4 weeks significantly lowered both blood eosinophil ratio and serum IgE levels, while any significant changes were observed in negative control $(p<0.05)$ (Fig. 4). These results indicated that RM-3 and RME could decrease allergic response in AD-like skin lesions induced by
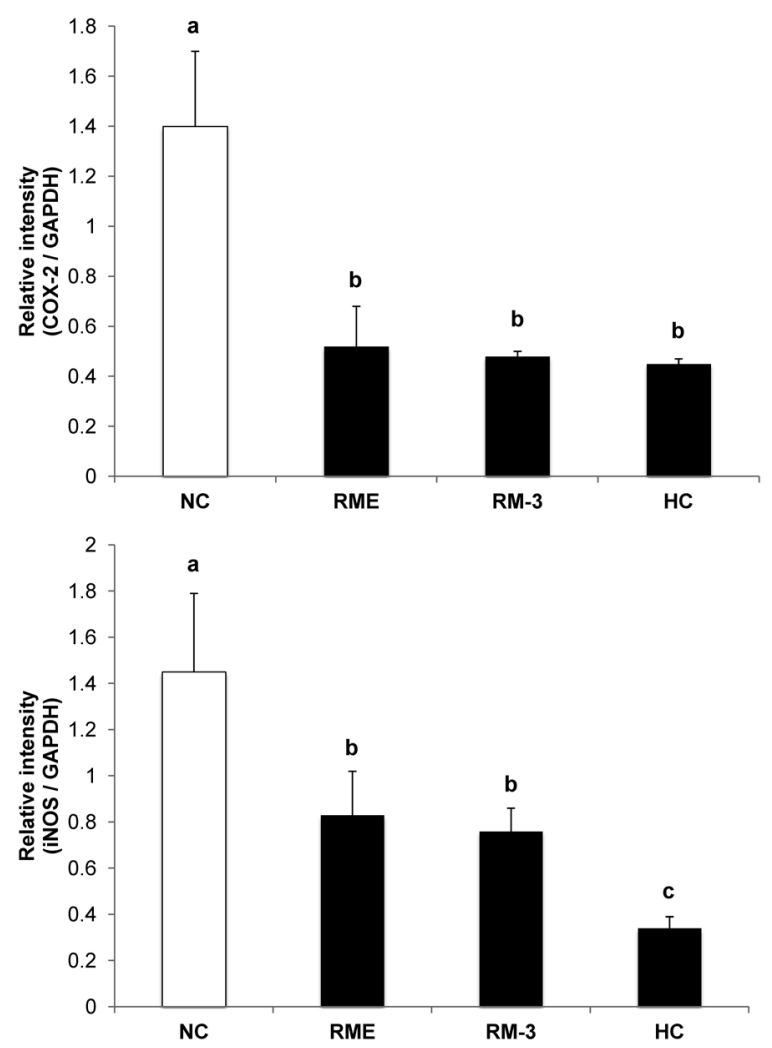

Fig. 3. Effects of RM-3 and RME on mRNA Levels of iNOS and $\mathrm{COX}-2$ in Skin Tissue of AD-like Skin Lesion Induced by Mite in NC/ Nga Mice

Results are expressed as mean \pm S.D. $(n=5)$. Values bearing different superscripts are significantly different $(p<0.05)$. NC, negative control; HC, hydrocortisone.
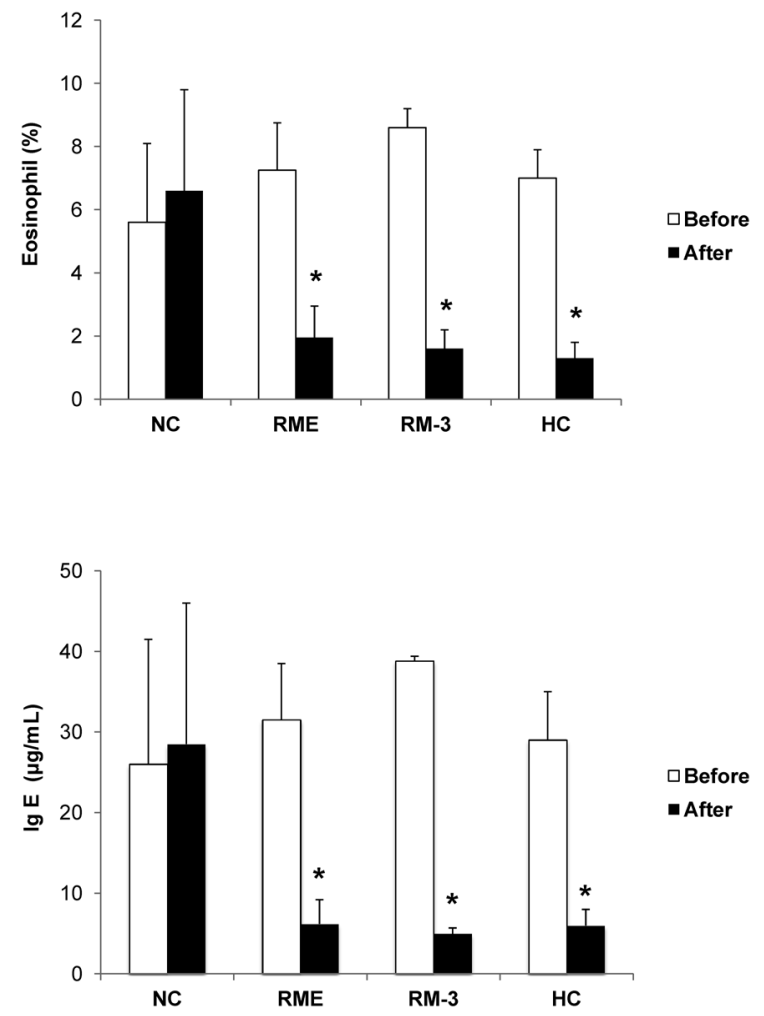

Fig. 4. Changes in Eosinophil Ratio and $\operatorname{IgE}$ Level before and after Topical Application of RM-3 and RME

Results are expressed as mean \pm S.D. $(n=5) .{ }^{*} p<0.05$ versus each group before treatment with sample. NC, negative control; $\mathrm{HC}$, hydrocortisone. 

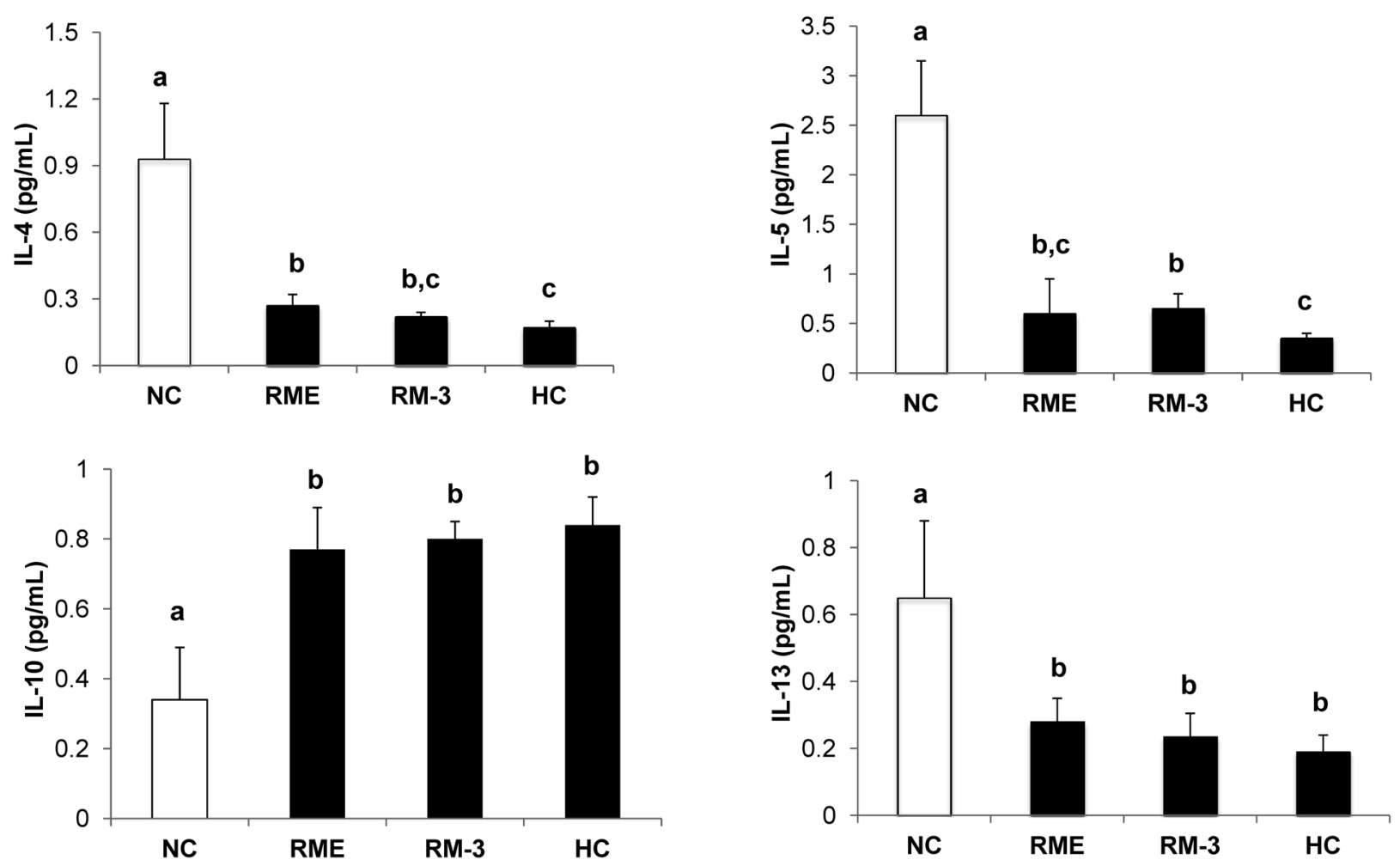

Fig. 5. Effects of RM-3 and RME on Serum Th2 Cytokine Levels in NC/Nga Mice

Results are expressed as mean \pm S.D. $(n=5)$. Values bearing different superscripts are significantly different $(p<0.05)$. NC, negative control; HC, hydrocortisone.

mite on NC/Nga mice.

Effects on Th2 Related-Cytokine Production Next, Th2 cytokines that has been known to regulate $\mathrm{AD}$ were also quantified in the serum of NC/Nga mice using ELISA. ${ }^{10)}$ Both RM-3 and RME reduced the serum levels of Th2 cytokines (IL-4, 5 and 13) compared with negative control, significantly $(p<0.05)$ (Fig. 5). In contrary, serum IL-10 level was significantly elevated by the topically treatment of RM-3 and RME as same degree of positive control, hydrocortisone $(p<0.05)$ (Fig. 5). These results suggested that RM-3 and RME might effectively regulate $\mathrm{Th}$-immune response like hydrocortisone on mite-stimulated $\mathrm{NC} / \mathrm{Nga}$ mice.

\section{DISCUSSION}

RME has been used as folk medicine on the treatment of scabies, rheumatism and stomatitis. It indicated that RME might possess anti-mite, anti-inflammatory and anti-allergic effects, related with major feature of remedy for today's AD. ${ }^{11)}$ Previously, several condensed tannins were isolated from RME, and a few of them (RM-1 and ProB3) improved AD-like skin lesion induced by mite on NC/Nga mice., ${ }^{4,5}$ RM-3, phlobatannin which has been reported to rare form of condensed tannins, can be simply explained to originate from condensation of ent-guibourtinidol- $(4 \beta \rightarrow 6)$-catechin (RM-1) on the processing of recyclization involving $5-\mathrm{OH}$ in catechin moiety and C-2 in guibourtinidol moiety. ${ }^{12)}$ This molecule showed potent 1,1-diphenyl-2-picrylhydrazyl (DPPH) radical scavenging activity and inhibitory activity on nitric oxide production in lipopolysaccharide (LPS)-stimulated RAW264.7 cells. ${ }^{4)}$ Therefore, RME, together with RM-3, were evaluated on AD-like skin lesions induced by mite on NC/Nga mice in this study.
NC/Nga mice, well-known as AD mouse model, reported to show clinical signs resemble to allergic eczema under conventional conditions, and possess similar traits to human AD such as increased serum IgE levels, chronic dryness and severe pruritis. It was reported that the $\operatorname{IgE}$ levels start to increase at 8 weeks of ages, the appearance of skin lesion peaks around 17 weeks in $\mathrm{NC} / \mathrm{Nga}$ mice under conventional conditions. However, low incidence of AD-like skin lesion or curing it by itself has been problem of this mouse model and resulted to a lack of reproducibility. ${ }^{13)}$ Thus, we attempted to treat mite antigen on the back of each mouse until 18 weeks of age for overcoming this obstacle. ${ }^{14)}$ From this way, AD-like skin lesions begun to appear after 1-2 weeks later from the treatment of mite antigen to 5 week-old $\mathrm{NC} / \mathrm{Nga}$ mice and got worse gradually until 18 weeks of age (data not shown). Several AD symptoms were rarely observed after 1-2 weeks from the topical application of both RM-3 and RME, and any signs were not observed at the end of experimental period as same degree of positive control, hydrocortisone. These results demonstrated that RM-3 and RME might be helpful to improve the AD symptoms, effectively.

iNOS and COX-2, play a role to produce nitric oxide and prostaglandin respectively, are well-known to mediate inflammatory or immune reactions. They markedly expressed in response to stimulation by several antigens or pro-inflammatory cytokines, thus measurement of suppression iNOS and COX-2 is considered the universal method for examining antiinflammatory effects. In this study, both RM-3 and RME also decreased mRNA levels of iNOS and COX-2 in the skin tissue compared to negative control. And, these results demonstrated that topical application of RM-3 and RME might effectively reduce inflammatory response induced by mite antigen in ADlike skin lesion of $\mathrm{NC} / \mathrm{Nga}$ mice. 
AD is characterized by abnormalities between Th1 and Th2 cytokines. That is, cases in which the balance of Th1/Th2 is slanted to Th2 correspond to Type 1 allergy in association with the occurrence of acute atopy. ${ }^{10)}$ These Th2 cytokines then promptly induce the allergic reaction in AD. IL-4 triggers the initial differentiation of naïve T-helper type 0 (Th0) lymphocytes toward a Th2 phenotype, and induces the immunoglobulin isotype switch from $\operatorname{IgM}$ to $\operatorname{IgE} .^{15,16)}$ In addition, IL-4 induces expression of VCAM-1 on endothelial cells in allergic inflammation, resulting to enhance adhesiveness of endothelium for $\mathrm{T}$ cells, eosinophils, basophils, and monocytes, as is characteristic of allergic reactions. ${ }^{17)} \mathrm{IL}-13$, a homologous to IL-4, is also reported to induce the $\operatorname{IgE}$ isotype switch and VCAM-1 expression. ${ }^{18)}$ In addition, IL-5 is the most important in induction of eosinophila; activates mature eosinophil, induces eosinophil secretion and prolongs eosinophil survival. ${ }^{19)}$

Meanwhile, IL-10 has been reported to derive from Th2 lymphocyte to inhibit Th1 differentiation in classical paradigm. However, recent studies suggested the primary T-cell source for IL-10 is Th3 (also referred to as Tr1), and IL-10 suppress Th1 as well as Th2 immune responses. ${ }^{20)}$ Especially, IL-10 is reported to inhibit eosinophil survival and IL-4-induced IgE synthesis. ${ }^{21)}$ In addition to above immunesuppressive role, IL-10 is well-known to typical anti-inflammatory cytokine. IL-10 induces 'suppressors of cytokine signaling 1 (SOCS1)' can directly inhibit interferon (IFN)- $\gamma$ signaling pathways via activation Janus kinase (JAK)/signal transducer and activator of transcription (STAT) pathway, and also inhibits nuclear factor $-\kappa \mathrm{B}(\mathrm{NF}-\kappa \mathrm{B})$, transcription factor that controls the expression of many inflammatory proteins such as iNOS and COX-2.22,23) Therefore, our results suggested that elevation of serum IL-10 level by topical application of RM-3 and RME on AD-like skin lesion induced by mite in NC/Nga mice might down-regulate Th2 cytokines (IL-4, 5 and 13)-mediated hyper-productions of $\operatorname{IgE}$ and eosinophils, and lower inflammatory response to expression of iNOS and COX-2.

There have been a lot of reports about anti-inflammatory and anti-allergic activities of condensed tannins (refer to proanthocyanidins), which are polymers of flavan 3-ols, and can be found in many plants, most notably apples, cocoa beans, grapes cranberry, red wine, black tea and green tea. ${ }^{24)}$ For example, they inhibited phosphorylation of mitogen-activated protein kinase (MAPK) proteins and the DNA binding of $\mathrm{NF}-\kappa \mathrm{B}$ in various experimental inflammatory conditions. ${ }^{25)}$ And, they suppressed the expression of $\operatorname{IgE}$ receptors on human mast cells, and also reduced serum IgE levels in mice immunized with ovalbumin. ${ }^{26,27)}$ Especially, more recent study explained that condensed tannins induced Foxp3 and IL-10 expression in Jurkat $\mathrm{T}$ cells and increased $\mathrm{Tr} 1$ frequencies and numbers in vivo. ${ }^{28)}$ Therefore, RM-3 might reduce oxidative stress and pro-inflammatory signaling pathway in skin allergic inflammation, and activate Treg, leads to down-regulate Th2 cytokines-mediated immune system in this study.

Several condensed tannins such as CAT, ProB3, RM-1, RM-2, and RM-3 were isolated from RME in our previous work, and those condensed tannins were contained as 54.8, $30.2,26.8,85.1$ and $17.4 \mu \mathrm{g}$ in $1 \mathrm{mg}$ of RME, respectively and sum of them was over $20 \mathrm{w} / \mathrm{w} \%$ on quantification by HPLC. Thus, the potent immune-regulatory effect of RME might be derived from rich accumulated condensed tannins.
Topical application of RM-3 as well as RME exhibited to improve mite-induced AD-like skin lesions in NC/Nga mice. They also lowered skin inflammatory response reducing mRNA levels of iNOS and COX-2, and normalized mite antigen-stimulated Th2-mediated immune systems by suppressing Th2 cytokines (IL-4, 5 and 13), blood eosinophil ratio and serum IgE level via activation of Treg such as up-regulation of IL-10. And, these anti-inflammatory and immune regulatory effects of RME might be contributed from several condensed tannins including RM-3 which were major constituents from RME. These results demonstrate that RME, natural source containing rich condensed tannins, may be useful for treatment of skin allergies, and can be developed as an alternative herbal medicine against AD.

Acknowledgments This research was supported by the Chung-Ang University Research Scholarship Grants in 2012.

\section{REFERENCES}

1) Leung DYM. Atopic dermatitis: new insights and opportunities for therapeutic intervention. J. Allergy Clin. Immunol., 105, 860-876 (2000).

2) Leung AK, Barber KA. Managing childhood atopic dermatitis. Adv. Ther., 20, 129-137 (2003).

3) Kim CM, Shin MK, Ahn DK, Lee KS. An Unabridged Dictionary of Chinese Herbs. Jeongdam Publishing House, Seoul, pp. 4735-4738 (1998).

4) Park KH, Kim SK, Choi SE, Kwon JH, Oh MH, Lee MW. Three new stereoisomers of condensed tannins from the roots of Rosa multiflora. Chem. Pharm. Bull., 58, 1227-1231 (2010).

5) Park KH, Choi SE, Choi YW, Lee DI, Joo SS, Jeong MS, Bang HW, Lee CS, Lee MK, Seo SJ, Lee MW. Topical application of two condensed tannins from the root of Rosa multiflora THUNBERG for the treatment of atopic dermatitis (AD) in NC/Nga mice. Phytother. Res., 25, 1564-1569 (2011).

6) Kunz B, Oranje AP, Labrèze L, Stalder JF, Ring J, Taïeb A. Clinical validation and guidelines for the SCORAD index: consensus report of the European Task Force on Atopic Dermatitis. Dermatology, 195, 10-19 (1997).

7) Vane JR, Mitchell JA, Appleton I, Tomlinson A, Bishop-Bailey D, Croxtall J, Willoughby DA. Inducible isoforms of cyclooxygenase and nitric-oxide synthase in inflammation. Proc. Natl. Acad. Sci. U.S.A., 91, 2046-2050 (1994).

8) Rousset F, Robert J, Andary M, Bonnin JP, Souillet G, Chrétien I, Brière F, Pène J, de Vries JE. Shifts in interleukin-4 and interferongamma production by $\mathrm{T}$ cells of patients with elevated serum $\operatorname{IgE}$ levels and the modulatory effects of these lymphokines on spontaneous IgE synthesis. J. Allergy Clin. Immunol., 87, 58-69 (1991).

9) Akdis CA, Akdis M, Trautmann A, Blaser K. Immune regulation in atopic dermatitis. Curr. Opin. Immunol., 12, 641-646 (2000).

10) Grewe M, Bruijnzeel-Koomen CA, Schöpf E, Thepen T, LangeveldWildschut AG, Ruzicka T, Krutmann J. A role for Th1 and Th2 cells in the immunopathogenesis of atopic dermatitis. Immunol. Today, 19, 359-361 (1998).

11) Tupker RA, De Monchy JG, Coenraads PJ, Homan A, van der Meer JB. Induction of atopic dermatitis by inhalation of house dust mite. J. Allergy Clin. Immunol., 97, 1064-1070 (1996).

12) Steenkamp JA, Steynberg JP, Brandt EV, Ferreira D, Roux DG. Phlobatannins, A novel class of ring-isomerized condensed tannins. J. Chem. Soc. Chem. Commun., 23, 1678-1679 (1985).

13) Shiohara T, Hayakawa J, Mizukawa Y. Animal models for atopic dermatitis: are they relevant to human disease? J. Dermatol. Sci., 36, 1-9 (2004). 
14) Sasakawa T, Higashi Y, Sakuma S, Hirayama Y, Sasakawa Y, Ohkubo Y, Goto T, Matsumoto M, Matsuda H. Atopic dermatitis-like skin lesions induced by topical application of mite antigens in $\mathrm{NC} /$ Nga mice. Int. Arch. Allergy Immunol., 126, 239-247 (2001).

15) Vella A, Teague TK, Ihle J, Kappler J, Marrack P. Interleukin 4 (IL-4) or IL-7 prevents the death of resting T cells: Stat-6 is probably not required for the effect of IL-4. J. Exp. Med., 186, 325-330 (1997).

16) Romagnani S. Regulation and deregulation of human $\operatorname{IgE}$ synthesis. Immunol. Today, 11, 316-321 (1990).

17) Schleimer RP, Sterbinsky SA, Kaiser J, Bickel CA, Klunk DA, Tomioka K, Newman W, Luscinskas FW, Gimbrone MA Jr, Mclntyre BW, Bochner BS. IL-4 induces adherence of human eosinophils and basophils but not neutrophils to endothelium: association with expression of VCAM-1. J. Immunol., 148, 1086-1092 (1992).

18) Zurawski G, de Vries JE. Interleukin 13, an interleukin 4-like cytokine that acts on monocytes and B cells, but not on T cells. Iтmunol. Today, 15, 19-26 (1994).

19) Baatjes AJ, Sehmi R, Saito H, Cyr MM, Dorman SC, Inman MD, O'Byrne PM, Denburg JA. Anti-allergic therapies: effects on eosinophil progenitors. Pharmacol. Ther., 95, 63-72 (2002).

20) Weiss E, Mamelak AJ, La Morgia S, Wang B, Feliciani C, Tulli A, Sauder DN. The role of interleukin 10 in the pathogenesis and potential treatment of skin diseases. J. Am. Acad. Dermatol., 50, 657-675, quiz, 676-678 (2004).

21) Borish LC, Steinke JW. 2. Cytokines and chemokines. J. Allergy
Clin. Immunol., 111 (Suppl.), S460-S475 (2003).

22) Ding Y, Chen D, Tarcsafalvi A, Su R, Qin L, Bromberg JS. Suppressor of cytokine signaling 1 inhibits IL-10-mediated immune responses. J. Immunol., 170, 1383-1391 (2003).

23) Schottelius AJ, Mayo MW, Sartor RB, Baldwin AS Jr. Interleukin-10 signaling blocks inhibitor of kappaB kinase activity and nuclear factor kappaB DNA binding. J. Biol. Chem., 274, 31868-31874 (1999).

24) Souquet J, Cheynier V, Brossaud F, Michel M. Polymeric proanthocyanidins from grape skins. Phytochemistry, 43, 509-512 (1996).

25) Zhang WY, Liu HQ, Xie KQ, Yin LL, Li Y, Kwik-Uribe CL, Zhu XZ. Procyanidin dimer B2 [epicatechin- $(4 \beta \rightarrow 8)$-epicatechin] suppresses the expression of cyclooxygenase-2 in endotoxin-treated monocytic cells. Biochem. Biophys. Res. Commun., 345, 508-515 (2006).

26) Tamura S, Yoshihira K, Fujiwara K, Murakami N. New inhibitors for expression of $\operatorname{IgE}$ receptor on human mast cell. Bioorg. Med. Chem. Lett., 20, 2299-2302 (2010).

27) Takano F, Takata T, Yoshihara A, Nakamura Y, Arima Y, Ohta T. Aqueous extract of peanut skin and its main constituent procyanidin A1 suppress serum IgE and IgG1 levels in mice-immunized with ovalbumin. Biol. Pharm. Bull., 30, 922-927 (2007).

28) Wong CP, Nguyen LP, Noh SK, Bray TM, Bruno RS, Ho E. Induction of regulatory $\mathrm{T}$ cells by green tea polyphenol EGCG. Immunol. Lett., 139, 7-13 (2011). 